\title{
Physicochemical, Rheological, and Sensory Properties of Gluten-Free Cookie Produced by Flour of Chestnut, Date Seed, and Modified Starch
}

\author{
Mehrdad Mohammadi (D), ${ }^{1}$ Nasim Khorshidian ${ }^{D}$, ${ }^{1}$ Mojtaba Yousefi $\left(\mathbb{D}^{2}{ }^{2}\right.$ \\ and Amin Mousavi Khaneghah $\mathbb{D}^{3}$ \\ ${ }^{1}$ Department of Food Technology Research, National Nutrition and Food Technology Research Institute, \\ Faculty of Nutrition Sciences and Food Technology, Shahid Beheshti University of Medical Sciences, Tehran, Iran \\ ${ }^{2}$ Food Safety Research Center (Salt), Semnan University of Medical Sciences, Semnan, Iran \\ ${ }^{3}$ Department of Food Science, Faculty of Food Engineering, University of Campinas (UNICAMP), Campinas, SP, Brazil
}

Correspondence should be addressed to Nasim Khorshidian; nkhorshidian@semums.ac.ir and Amin Mousavi Khaneghah; mousavi@unicamp.br

Received 1 September 2021; Revised 26 November 2021; Accepted 30 December 2021; Published 2 February 2022

Academic Editor: Shudong He

Copyright $\odot 2022$ Mehrdad Mohammadi et al. This is an open access article distributed under the Creative Commons Attribution License, which permits unrestricted use, distribution, and reproduction in any medium, provided the original work is properly cited.

\begin{abstract}
A gluten-free rice flour-based cookie was produced using different mixtures of chestnut flour $(0,30,40$, and $50 \%)$, date seed flour $(0,10$, and 20\%), and modified starch $(0.3,0.5,0.6$, and $0.9 \%)$. Physicochemical, rheological, and sensory properties of the prepared treatments were investigated. The results showed that moisture, specific volume, and dough viscosity were the lowest in control and the highest in treatment $\mathrm{T} 1$ containing $20 \%$ date seed flour, $30 \%$ chestnut flour, and $0.9 \%$ modified starch $(P<0.05)$. The highest $(22.15 \mathrm{~N})$ and the lowest hardness $(13.5 \mathrm{~N})$ were obtained in the control and T1, respectively, both of which increased over the storage time $(P<0.05)$. Regarding the texture characteristics of different dough treatments, the control illustrated the lowest adhesiveness and the highest hardness and chewiness. Sensory evaluation revealed that gluten-free treatments were acceptable from the consumers' point of view. It was concluded that T1 as a gluten-free cookie had the highest quality.
\end{abstract}

\section{Introduction}

Coeliac or celiac disease (CD) is among the most common chronic diseases worldwide that emerge in individuals genetically susceptible to gluten resulting in enteritis and nutrient malabsorption. Consumption of prolamines found in cereals like wheat, barley, rye, some oat cultivars, and their derivatives has been reported as the leading cause of this disease [1]. Adherence to a gluten-free (GF) diet is proposed for CD treatment. According to Codex Alimentarius, "GF" label can be applied only for foods made of GF ingredients containing less than $20 \mathrm{ppm}$ gluten [2].

Producing GF food products, especially those with acceptable functional and sensory properties, is a great challenge since gluten is responsible for the structure of these products, and the limited availability of GF products indicates this difficulty [3-5]. To prevail this issue, utilization of various GF flours (rice, maize, and sorghum), pseudocereals (quinoa, amaranth, and buckwheat), legumes (soybean, chickpea, and carob germ flour), starches (corn, potato, cassava, and modified starch (MS)), hydrocolloids, and proteins have been investigated to modify GF products' technological, sensory, and nutritional features $[6,7]$.

Cookies are extensively consumed throughout the world and are a good energy source for all age groups. They are available in different shapes and flavors with long shelf life and low cost. Moreover, they can be produced through GF formulations with excellent quality and sensory properties. There is no need for gluten network development, and the influential primary factor on the texture is the gelatinization 
of starch [8]. A large number of ingredients such as alfalfa seed [9], quinoa [10], and germinated pinto bean [11] flour as well as locust bean gum [12], xanthan gum [13], waxy rice starch [14], and pea protein [15] have so far been used as an alternative for wheat flour in the cookie recipe.

Rice flour is one of the most suitable cereals for developing gluten-free products due to its mild taste, colorlessness, hypoallergenic properties, low levels of sodium, and easily digestible carbohydrates [16]. However, one of the significant problems associated with GF bakery products is low nutritional quality as a result of the lower content of vitamins (folate and $\mathrm{B}_{12}$ ), minerals (iron, zinc, magnesium, and calcium), and dietary fibers [17] that can be addressed by adding suitable ingredients in the formulation such as chestnut flour and date seed flour.

Chestnut is composed of water, carbohydrate, and a low quantity of fat. Chestnut flour (CF) is used for producing GF foods such as GF bread and biscuit [18-26]. Its composition is near to cereal flours regarding the amount of starch $(40-50 \% \mathrm{w} / \mathrm{w})$; however, its sucrose content is higher (20-32\%) [27]. Besides, it is a good source of essential amino acids, dietary fibers, vitamin E, vitamin B group, potassium, phosphorous, and magnesium and contains low-fat content mainly composed of unsaturated ones and phenolic compounds and vitamins [28].

Modified starch (MS) could be used as a substitute for wheat starch as it influences water absorption and rheological properties of the dough, degree of starch gelatinization, texture, and bread staling [29-31]. Reports show that modified starch is used in GF bakery products like high amylose corn starch, acetylated distarch adipate, and hydroxypropyl distarch phosphate in GF bread [32]; pregelatinized tapioca starch in rice bread [33]; and maltodextrin [34]. In the heat-moisture treatment of starch, the granular shape is maintained at heating above $100^{\circ} \mathrm{C}$ in the presence of water. Heat-moisture treatment starch increases the stability to mechanical agitation, increases the hydrophobicity, and decreases the hydrophilicity of starch paste [35].

Date palm (Phoenix dactylifera L.) mainly grows in the Middle East and North Africa. The date is a nutritious and high-energy food. Date seeds contain significant dietary fiber and micronutrients such as selenium, iron, calcium, phenolic compounds, mainly flavonoids, sterols, tocopherols, metal ions, and essential amino acids. Date seed is considered a good source of bioactive ingredients in the formulation of functional foods. Date seed flour (DSF) has been used as an alternative for wheat flour in pita bread preparation because it increases the formulated product's phenolic compounds and dietary fiber [36].

The literature review shows no investigation of the influence of different CF, DSF, and MS combinations on the GF cookies. The reason could be that the date mainly grows in the Middle Eastern countries, including Iran. Hence, the present research attempts to develop a GF rice flour (RF)based cookie using different CF, DSF, and MS levels and determine their effect on the cookie.

\section{Materials and Methods}

2.1. Materials. Rice, Fajr cultivar, purchased from a market in Rasht city, Iran, was soaked in water, ground, and then passed through an 80 -mesh sieve. The obtained flour was heated in an oven at $45^{\circ} \mathrm{C}$ to reach the moisture content of $10 \%$. Sugar, shortening, eggs, vanilla powder, and baking powder were obtained from the local supermarkets in the same city.

In order to prepare CF, European chestnut (Castanea sativa) fruits were purchased from a local market. Then, they were added to boiling water to facilitate peeling and reducing bitterness. After drying and peeling the fruits, they were ground, and the fine flour with $180-200 \mu \mathrm{m}$ was obtained after sieving. In order to prepare DSF, seed powder of date, Shahani cultivars, was purchased from Minoo Co. (Shiraz, Iran). Then, it was ground, and the fine flour with 300-500 um was obtained after sieving. The heat-moisture method was applied to modify wheat starch [37].

2.2. Cookie Preparation. The ingredients used for the preparation and treatment of cookies are presented in $\mathrm{Ta}-$ ble 1. Initially, shortening and sugar were mixed for $3 \mathrm{~min}$. Then, we added water, eggs, and MS and mixed them all for $5 \mathrm{~min}$. Next, RF and other powdered ingredients were added and mixed to achieve a dough flattened into sheets of $0.6 \mathrm{~cm}$ thickness. Next, it was allowed to rest for $30 \mathrm{~min}$ at $4^{\circ} \mathrm{C}$. Afterward, it was cut using a circular mold ( $4.5 \mathrm{~cm}$ diameter) and baked at $180^{\circ} \mathrm{C}$ for $14 \mathrm{~min}$. Then, all cookies were cooled down and maintained in distinct sealed bags at room temperature. For each formulation, three batch replicates were produced. GF cookies were prepared based on the control method by adding CF and DSF.

2.3. Physicochemical Analysis. Moisture (Method 44-19) was measured using the AACC method. The specific volume of treatments was calculated by the method of rapeseed displacement $2 \mathrm{~h}$ after baking [38] as follows:

$$
\text { specific volume }\left(\mathrm{cm}^{3} / \mathrm{g}\right)=\frac{\text { volume displacement by each treatment }}{\text { weight of each treatment }} .
$$


TABle 1: Quantities of variable ingredients $(g)$ used in the formulation of cookies doughs.

\begin{tabular}{lcccc}
\hline Treatments $^{\mathrm{A}}$ & Rice flour & CF & DSF & MS \\
\hline Control $^{\mathrm{B}}$ & 100 & 0 & 0 & 0.5 \\
T1 & 50 & 30 & 20 & 0.9 \\
T2 & 50 & 40 & 10 & 0.9 \\
T3 & 50 & 50 & 0 & 0.9 \\
T4 & 50 & 30 & 20 & 0.6 \\
T5 & 50 & 40 & 10 & 0.6 \\
T6 & 50 & 50 & 0 & 0.6 \\
T7 & 50 & 30 & 20 & 0.3 \\
T8 & 50 & 40 & 10 & 0.3 \\
T9 & 50 & 50 & 0 & 0.3 \\
\hline
\end{tabular}

${ }^{\text {A }}$ The other ingredients $(g)$ in all treatments: sugar: 45 , shortening: 30 , water: 20, egg: 8, baking powder: $0.9, \mathrm{NaHCO}_{3}: 0.75 .{ }^{\mathrm{B}} \mathrm{Control}$ (cookie without $\mathrm{CF}$ and DSF).

Color analysis was performed using HunterLab ColorFlex EZ (USA) in three different zones of the crust, and the output was reported as three measurements' average using the values of CIE $L *, a *$, and $b * . L *$ is indicative of lightness varying from 0 (black) to 100 (perfect white), whereas $a *$ and $b *$, respectively, illustrate +redness/ -greenness and +yellowness/-blueness [39].

2.4. Dough Viscosity Measurement. Apparent viscosity (mPa.s) of different dough treatments was measured using Brookfield viscometer (Model DVII, USA). Spindle No. 7 was set to $10 \mathrm{rpm}$. We used spindle No. 7 for all experiments, and viscosity measurement was conducted at room temperature $\left(25 \pm 1{ }^{\circ} \mathrm{C}\right)$.

2.5. Textural Analysis. Textural analysis of different treatments was determined for hardness, adhesiveness, and chewiness using a TA. XTplus texture analyzer (Stable Micro Systems, UK) [40]. Hardness was determined on the 1st and 4th days after baking. Texture properties were determined 6 times for each treatment. The peak force to snap the treatments was reported as fracture force in "N."

2.6. Sensory Evaluation. Sensory analysis of fresh treatments was done on a baking day by 10 male and 10 female trained assessors comprising technicians and laboratory members of the cookie producer company with ages ranging from 30 to 45 years in separate booths. Three-digit random codes were assigned to the treatments and were assessed for flavor, firmness, chewing ability, and overall acceptability based on a 5 -score hedonic scale (like extremely $=5$ and dislike significantly $=1$ ). Bottled water at room temperature was also provided to clean the palate between the treatments [41].

2.7. Statistical Analysis. All statistical analyses were performed by the SPSS software (ver. 22) (IBM Corporation, Somers, NY). Data were presented as $M \pm \mathrm{SD}$ and analyzed by the ANOVA. Duncan's multiple range test was used to determine significance between means. Differences at $p<0.05$ were considered to be significant.

\section{Results and Discussion}

3.1. Physicochemical Characteristics. Moisture content substantially influences the cookies' mechanical strength (crumbliness) and crunchiness. As shown in Figure 1, the control has the lowest moisture content (35.5\%) compared to other treatments $(p<0.05)$. Furthermore, T1 showed the highest moisture content (51\%) among all treatments $(p<0.05)$. This can be attributed to the high protein and fiber content in DSF and CF and the presence of hydroxyl groups that enhanced the capability of interaction with water molecules and thus increased moisture content. The high MS $(0.9 \%)$ level also contributed to maintaining the moisture within these treatments.

Reference [42] found an increase in the moisture amount of bread containing guar gum because of hydrocolloids' high water holding capacity. According to [43], CF exhibited higher water holding capacity than other GF flours for its higher fiber content. Moreover, it has been declared that CF contained a high level of damaged starch, which increased water absorption [44].

Bakery product volume is a crucial factor influencing consumer acceptability. Many GF products are formulated with RF; however, the lack of gluten in RF decreases $\mathrm{CO}_{2}$ retention [45]. The influence of RF replacement by CF, DSF, and MS on a specific volume of treatments is demonstrated in Figure 2. The control and T1 showed the lowest $\left(2.85 \mathrm{~cm}^{3} /\right.$ g) and the highest $\left(4.6 \mathrm{~cm}^{3} / \mathrm{g}\right)$ values, respectively, compared to the other treatments $(p<0.05)$. Reference [46] mixed potato starch and CF to prepare GF cake. They reported that a specific volume of treatments decreased by increasing $\mathrm{CF}$ in the formulation. Likewise, as [47] mentioned, increasing the level of okara flour substitution in GF cookies decreased the specific volume because fibers interfered in the structure and gas retention, hindering the dough. It has also been expressed that increasing the protein content led to an increase in cake volume due to an increase in batters' viscoelasticity and the time the batters need to become semisolid. This can be attributed to protein-starch transition and interaction [48].

Protein and sugar interaction during baking ends with Maillard reaction and change of color values. Thus, a baked product's color, texture, and taste are important in consumers' acceptability. Figure 3 presents the $L *, a *$, and $b$ * values of prepared treatments with different flours. As shown, the control is brighter than other treatments, as indicated by higher $L^{*}$ values, and $\mathrm{T} 1$ has the lowest value. Concerning $a *$, T7 possesses the highest $a *$ value compared to other treatments $(p<0.05)$, except T3 and T9, whereas T5 showed the lowest $a^{*}$. As shown in Figure 3, the highest $b^{*}$ value is observed in T5 compared to other treatments $(p<0.05)$, and the lowest value belongs to T1. In terms of the recorded difference in total color $(\Delta \mathrm{E})$, the lowest and the highest values were T1 (47.48) and T5 (66.18), respectively $\left(p^{<} 0.05\right)$. It can be elucidated that incorporating different flours as gluten replacers reduced $L^{*}$ value and elevated $a^{*}$ value. A similar trend was observed by incorporating okara into the GF cookie, where a reddish color and an increased yellowness were achieved. In addition, a 


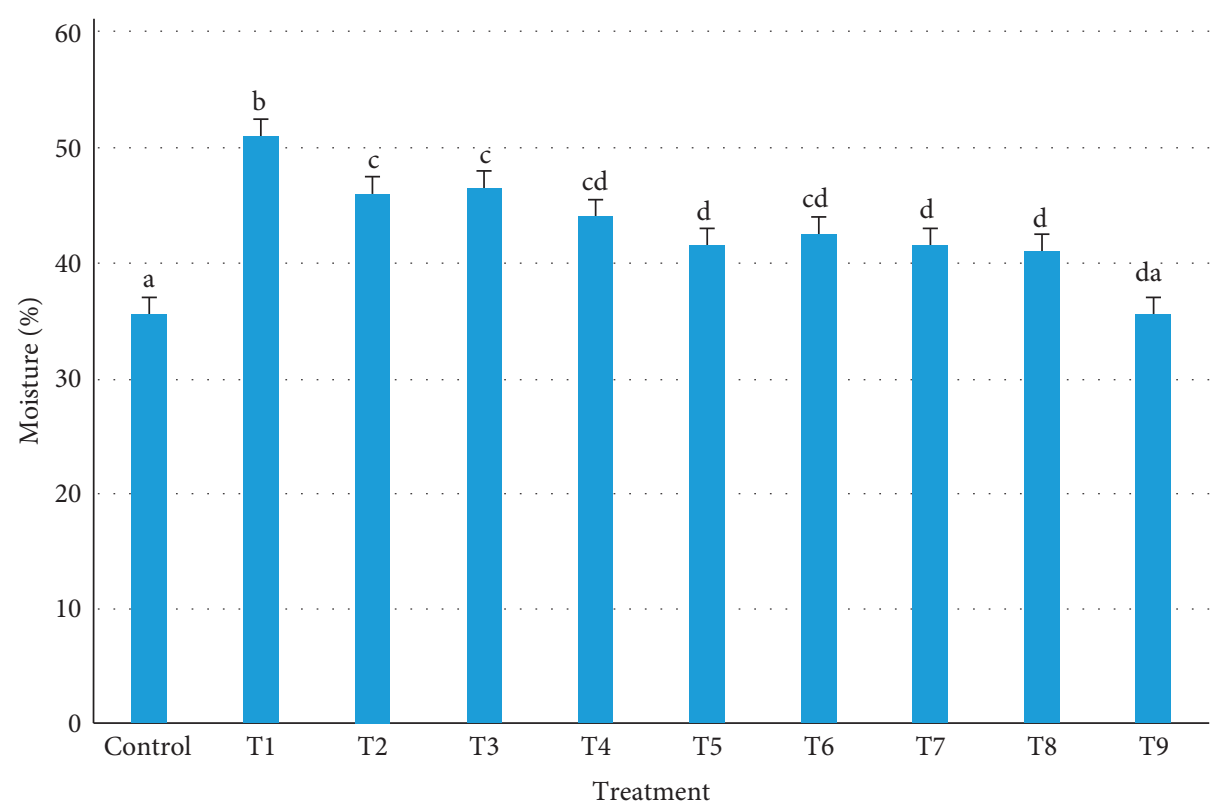

FIgURE 1: Moisture content of cookies prepared with varying levels of CF, DSF, and MS. For the treatments' descriptions, see Table 1. The treatments with different lowercase letters are significantly different $(p<0.05)$.

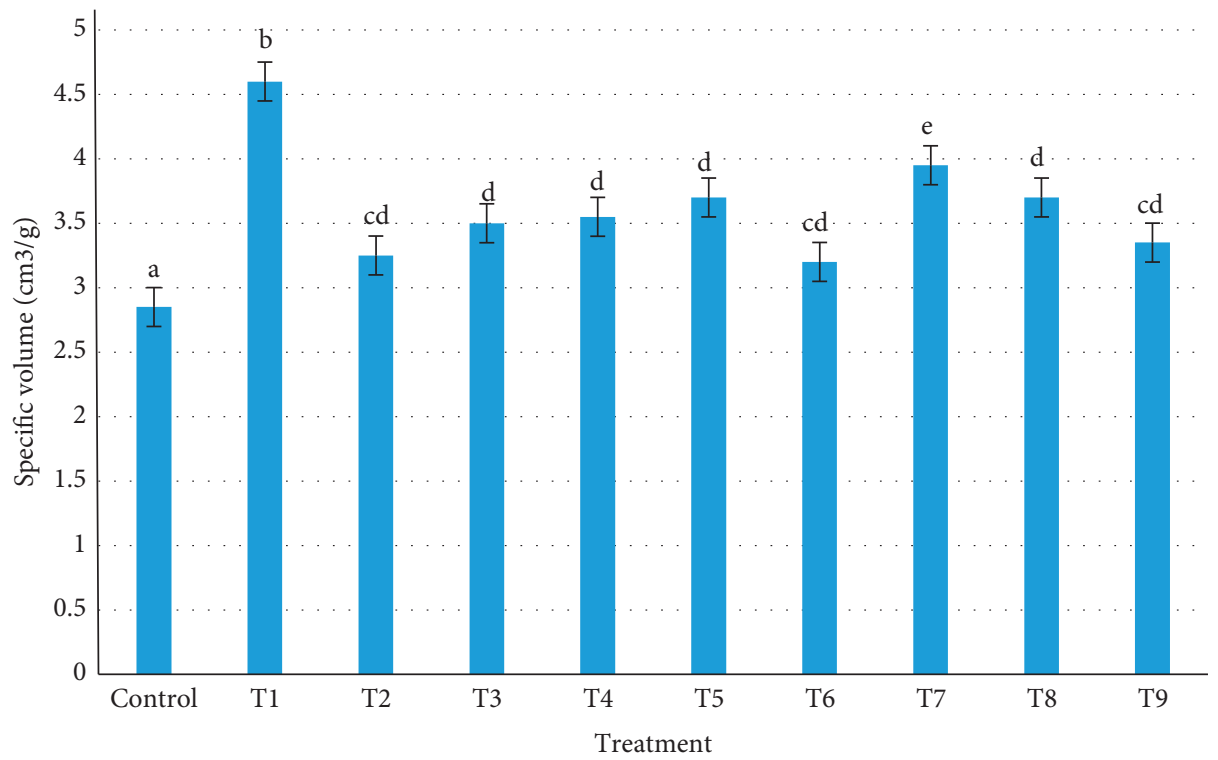

FIGURE 2: Specific volume of cookies prepared with varying levels of CF, DSF, and MS. For the treatments' descriptions, see Table 1. The treatments with different lowercase letters are significantly different $(p<0.05)$.

negative relation was found between the lightness of the cookie and protein content due to an increase in Maillard reaction [47].

Reference [18] stated that supplementation with CF in GF biscuits significantly lowered $L *$ and elevated $a *$ and $b *$. Similarly, [14] reported that addition of alfalfa seed flour to GF rice cookies decreased $L *$ and increased $a *$ and $b *$. The changes in color indices were attributed to the native pigmentation of flour and the Maillard reaction during baking. Reference [26] found that cookies containing CF indicated lower $L^{*}$ and higher values of $a *$ and $b *$ than the control justified by naturally darker color and higher sugar content of CF, leading to more browning during baking. This darker color was considered desirable since most GF products possess lighter colors than products with gluten. Moreover, consumer demand is higher for these dark-colored GF products [23]. In addition, [49] reported increased values of $a^{*}$ and $b *$ and decreased value of $L *$ by increasing the level of CF incorporated into cookies. 


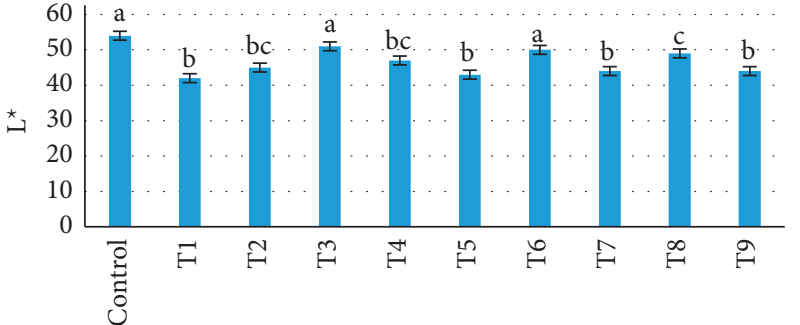

Treatment

(a)

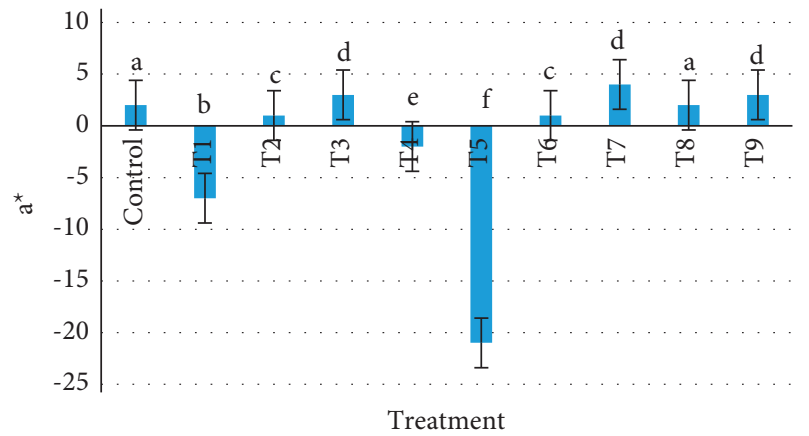

(c)

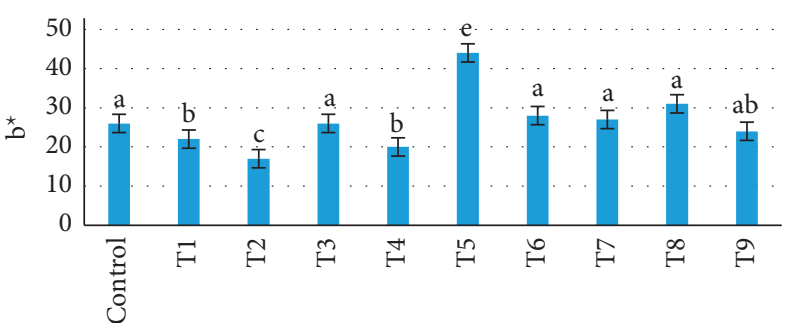

Treatment

(b)

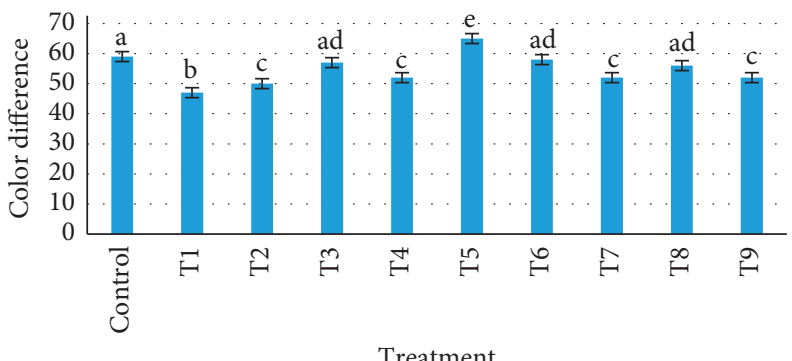

(d)

Figure 3: Color parameters of cookies prepared with varying levels of CF, DSF, and MS. For the treatments' descriptions, see Table 1. The treatments with different lowercase letters are significantly different $(p<0.05)$.

3.2. Apparent Viscosity of Cookie Dough. As shown in Figure 4 , the lowest and the highest viscosity were obtained in control $(442 \mathrm{cP})$ and $\mathrm{T} 1(2425 \mathrm{cP})$, respectively, compared to the other treatments $(p<0.05)$. This can be ascribed to the high hydroxyl groups in DSF and maintaining the water. Moreover, the fibrous structure of $\mathrm{CF}$ is the other reason influencing viscosity. Fiber entanglement also helps resist flow and increases the viscosity [23]. Reference [50] showed the viscosity increase of GF cake batters by increasing the quinoa flour content. The authors declared that the increase of viscosity was associated with the amount of water available in the system, which was influenced by the level of proteins in the flour. Since quinoa flour absorbed water, there was less free water for promoting particle movement in batters, leading to increased viscosity. The effect of flour's protein content on viscosity has been proved by some other researchers [48].

3.3. Texture Characteristics. Figure 5 indicates the effect of different flours on the hardness of treatments. As shown, by increasing the storage time, the hardness increases significantly. This increase is defined as the staling process for water departure from crumb to crust and starch recrystallization, which changes the bread texture [51]. On the first day of storage, the control showed the highest hardness $(22.15 \mathrm{~N})$, and $\mathrm{T} 1$ indicated the lowest hardness $(13.5 \mathrm{~N})$ $(p<0.05)$. Four days after storage, the highest $(22.39 \mathrm{~N})$ and lowest $(13.87 \mathrm{~N})$ hardness were observed in the control and
T1, respectively $(p<0.05)$. In line with our results, [26] illustrated that cookies prepared from RF demonstrated the highest hardness value due to the absence of enough viscosity to inhibit air bubble loss during baking. It was further mentioned that RF replacement with CF up to $40 \%$ decreased the hardness of cookies considerably [26]. According to [24], increasing the level of chestnut flour and xanthan-guar gum blend decreased the bread staling considerably by reducing the amylopectin retrogradation, bread hardness, and moisture loss. Similarly, [52] reported a decrease in cookie hardness by increasing the amount of chiku fiber added to cookie formulation.

Reference [53] pointed out that the mixture of CF and brown rice $(60: 40 \%)$ decreased GF snacks' hardness significantly. It was emphasized that the high sugar content of CF probably delayed starch gelatinization through interacting with starch linkages and reducing water activity that resulted in stabilization of the amorphous regions of starch granules and texture changes during frying. Reference [54] stated that the desirable texture of dry food products such as cookies could be destroyed during storage, possibly due to the recrystallization of sucrose in cookies with high sugar and low moisture that was confirmed by [55].

Results of the texture characteristics of dough treatments are demonstrated in Figure 6. The lowest hardness and chewiness were recorded in $\mathrm{T} 1$, while the highest values were observed in the control dough $(p<0.05)$. In the case of adhesiveness, T8 showed the highest value, while T6 and control exhibited the lowest values $(p<0.05)$. Reference [56] 


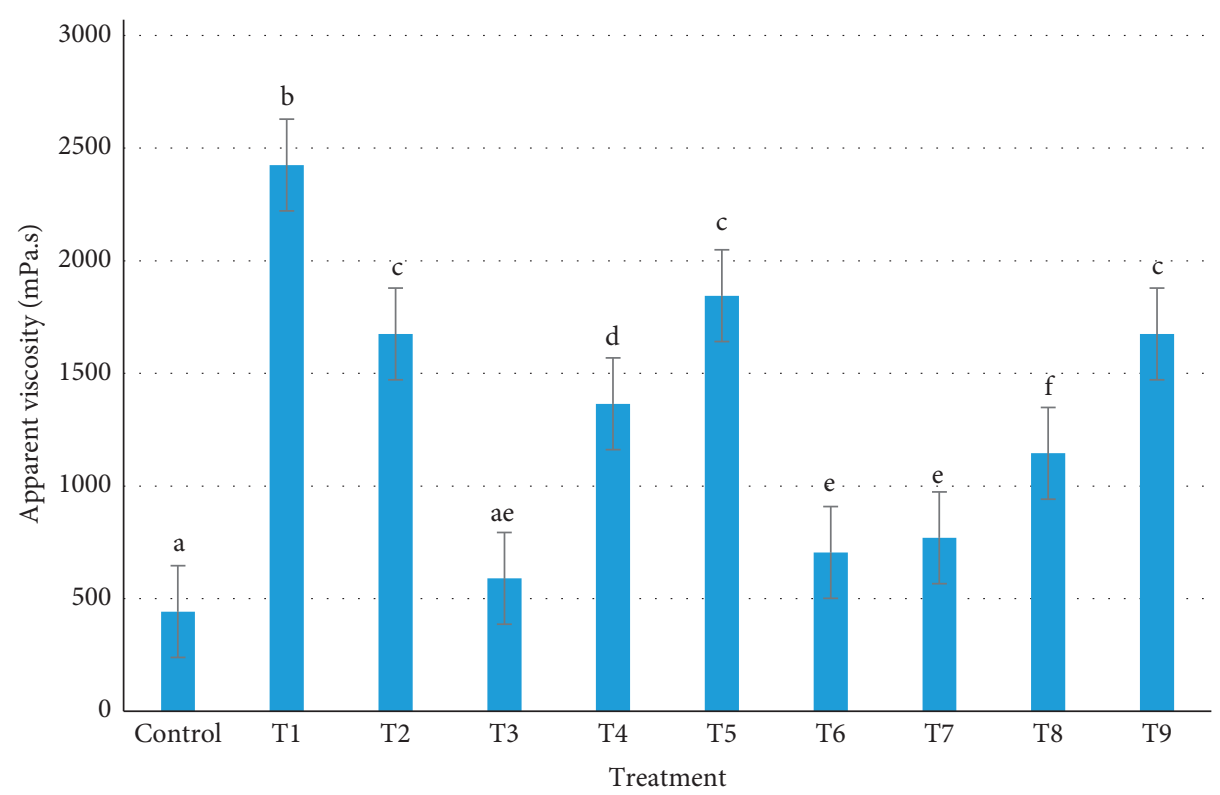

FIGURE 4: Apparent viscosity of cookies prepared with varying levels of CF, DSF, and MS. For the treatments' descriptions, see Table 1. The treatments with different lowercase letters are significantly different $(p<0.05)$.

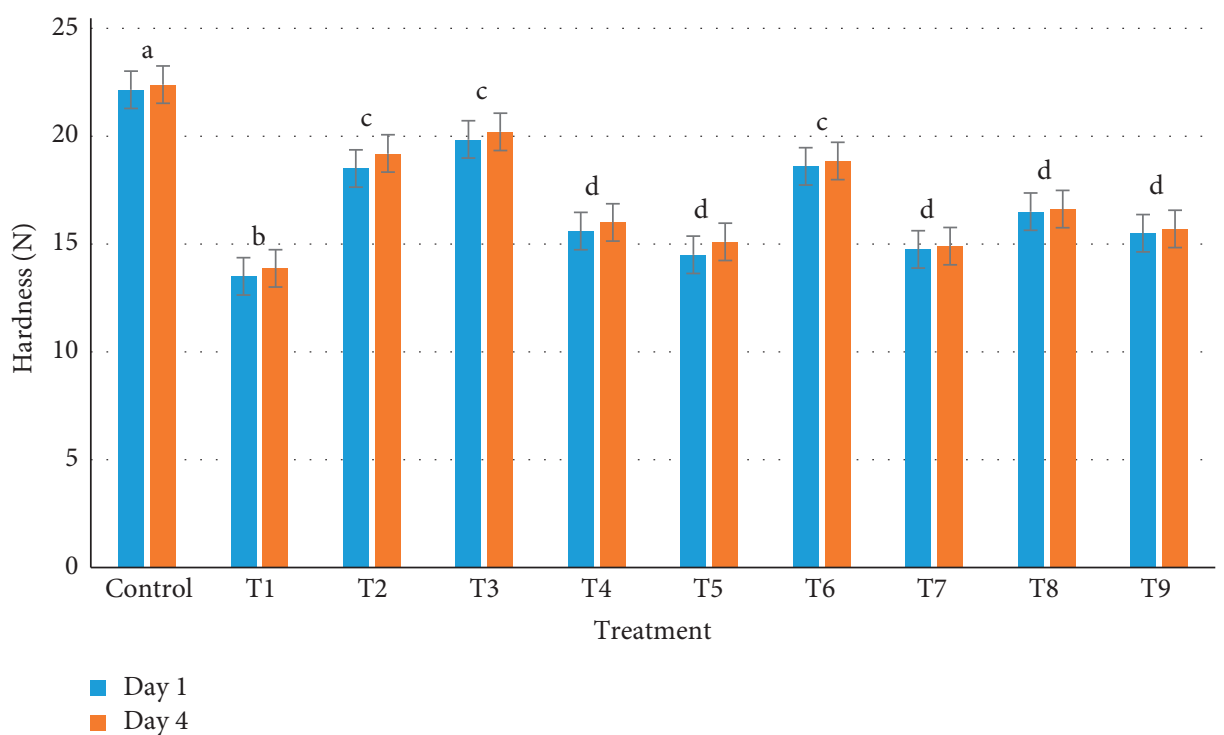

FIGURE 5: Hardness of cookies prepared with varying levels of CF, DSF, and MS during storage. For the treatments' descriptions, see Table 1. The treatments with different lowercase letters are significantly different $(p<0.05)$.

observed a change in GF cookies' textural properties by incorporating king palm flour. It has been noted that by adding king palm flour, the adhesiveness of dough treatments decreased compared to the control due to the existence of fibers. Incorporating fiber sources in bakery products increased the water binding capacity because of the hydroxyl groups existing in the fiber structure and facilitated hydrogen bonding with water, affecting textural characteristics [57].

3.4. Sensory Properties. Gaining favorable sensory characteristics is a tremendous challenge in developing GF products. GF products exhibit different appearances, colors, texture, aroma, and taste compared to wheat flour products. Generally, GF bakery products exhibit lower sensory acceptability due to the undesirable appearance, darker color, more complex texture, and dry sandy feeling in the mouth [41].

Table 2 indicates the influence of RF replacement with CF, DSF, and MS on GF treatments' sensory characteristics. The results illustrated that incorporating gluten replacers in cookie formulation had little influence $(p<0.05)$ on different treatments' flavor and chewing ability. The lowest scores were recorded in control and T2 concerning firmness, while the highest values were those of $\mathrm{T} 3$ and $\mathrm{T} 5$. The control and $\mathrm{T} 4$ showed the lowest overall acceptability, while $\mathrm{T} 6$ 


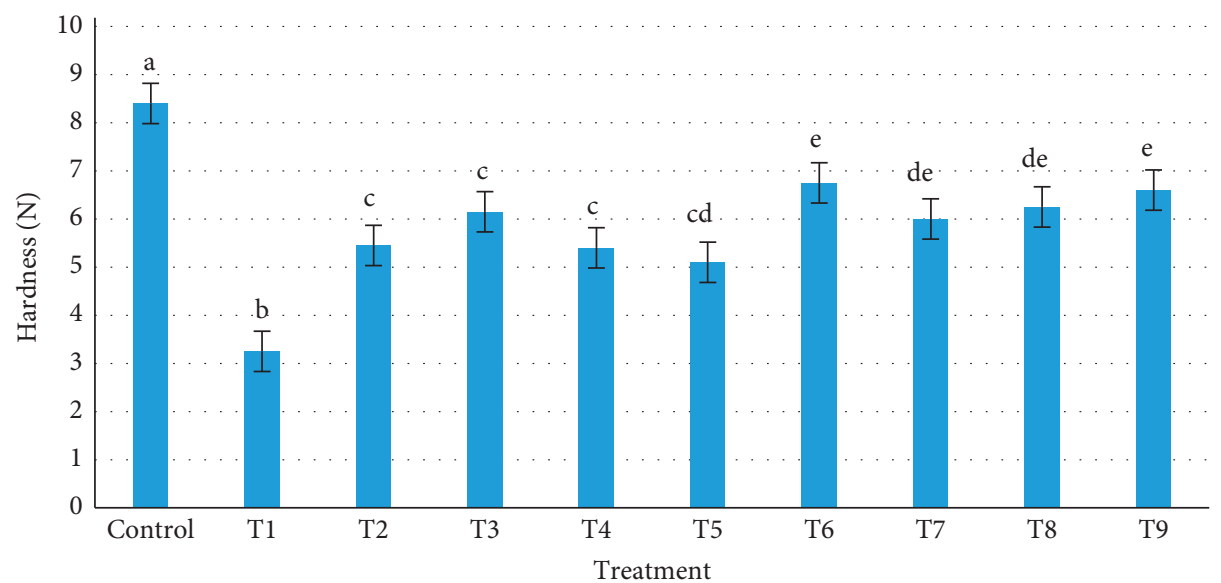

(a)

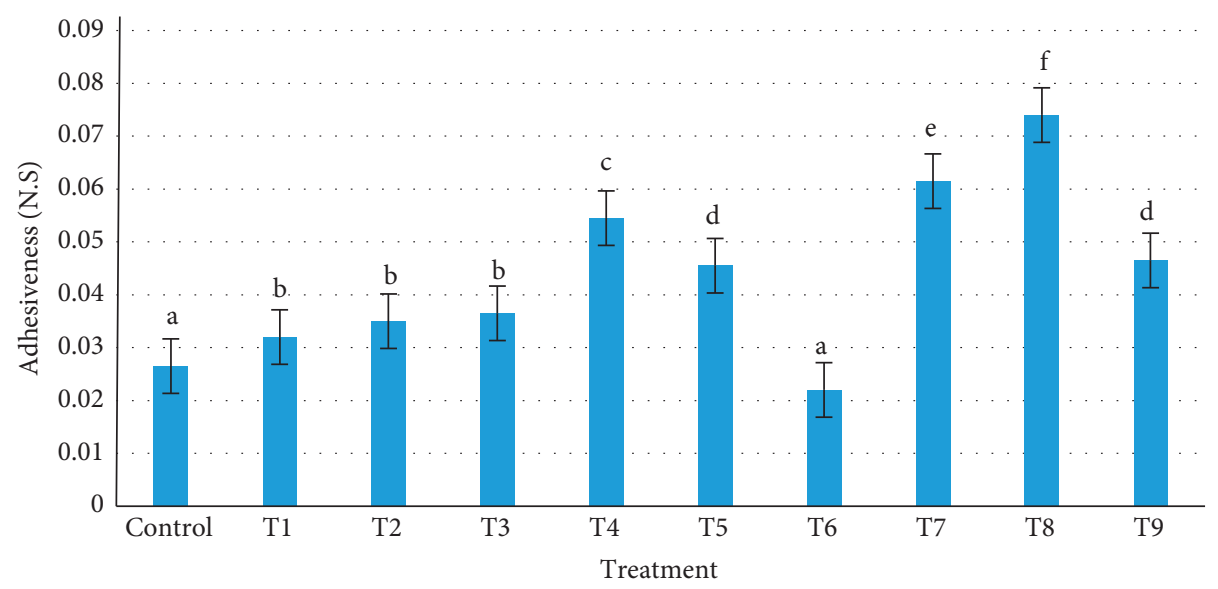

(b)

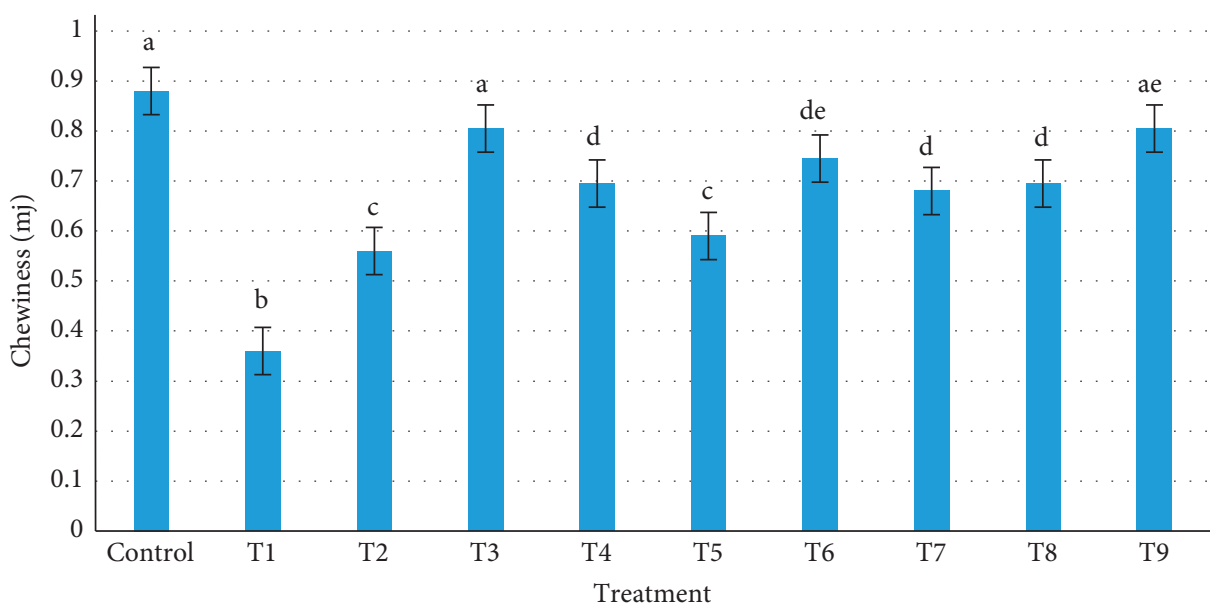

(c)

FIGURE 6: Textural characteristics of cookies prepared with varying levels of CF, DSF, and MS. For the treatments' descriptions, see Table 1. The treatments with different lowercase letters are significantly different $(p<0.05)$.

received the highest score $(p<0.05)$. Consistently, [58] expressed that treatments containing $100 \%$ RF demonstrated the lowest overall acceptability, but the incorporation of soybean flour improved the sensory characteristics. Besides, cookies containing $85 \% \mathrm{RF}$ and $15 \%$ soybean flour obtained the most significant overall acceptance. In the study [52], the addition of $7 \%$ concentrated chiku fiber powder to GF cookie resulted in the highest overall acceptability. Similarly, [41] reported that RF replacement with almond flour ended with higher overall acceptability scores by panelists. 
TABLE 2: Sensory characterization of GF cookies formulated with varying levels of CF, DSF, and MS.

\begin{tabular}{lcccc}
\hline Treatments $^{\mathrm{A}}$ & Flavor & Firmness & Chewing ability & Overall acceptability \\
\hline Control & $3.5 \pm 0.83^{\mathrm{a}}$ & $2.83 \pm 1.16^{\mathrm{a}}$ & $3.16 \pm 0.75^{\mathrm{a}}$ & $3.0 \pm 0.63^{\mathrm{a}}$ \\
T1 & $4.0 \pm 1.4^{\mathrm{a}}$ & $3.8 \pm 0.44^{\mathrm{b}}$ & $3.8 \pm 0.8^{\mathrm{a}}$ & $4.0 \pm 0.7^{\mathrm{b}}$ \\
T2 & $3.6 \pm 1.1^{\mathrm{a}}$ & $2.6 \pm 0.54^{\mathrm{a}}$ & $3.4 \pm 0.54^{\mathrm{a}}$ & $3.4 \pm 0.89^{\mathrm{b}}$ \\
T3 & $3.75 \pm 0.5^{\mathrm{a}}$ & $4.25 \pm 0.5^{\mathrm{c}}$ & $3.25 \pm 0.5^{\mathrm{a}}$ & $3.75 \pm 0.5^{\mathrm{b}}$ \\
T4 & $3.0 \pm 0.7^{\mathrm{a}}$ & $4.0 \pm 0.7^{\mathrm{ab}}$ & $3.6 \pm 0.89^{\mathrm{a}}$ & $3.0 \pm 0.11^{\mathrm{a}}$ \\
T5 & $3.6 \pm 1.1^{\mathrm{a}}$ & $4.2 \pm 0.44^{\mathrm{c}}$ & $3.2 \pm 0.83^{\mathrm{a}}$ & $3.8 \pm 1.0^{\mathrm{b}}$ \\
T6 & $3.6 \pm 1.1^{\mathrm{a}}$ & $3.4 \pm 0.89^{\mathrm{b}}$ & $3.6 \pm 1.1^{\mathrm{a}}$ & $4.2 \pm 0.83^{\mathrm{b}}$ \\
T7 & $3.83 \pm 0.75^{\mathrm{a}}$ & $3.5 \pm 1.0^{\mathrm{b}}$ & $3.83 \pm 0.75^{\mathrm{a}}$ & $3.83 \pm 0.4^{\mathrm{b}}$ \\
T8 & $3.25 \pm 0.95^{\mathrm{a}}$ & $3.25 \pm 1.5^{\mathrm{b}}$ & $3.5 \pm 1.29^{\mathrm{a}}$ & $3.5 \pm 1.0^{\mathrm{b}}$ \\
T9 & $4.0 \pm 1.1^{\mathrm{a}}$ & $3.8 \pm 1.3^{\mathrm{b}}$ & $3.4 \pm 1.1^{\mathrm{a}}$ & $3.4 \pm 0.54^{\mathrm{b}}$ \\
\hline
\end{tabular}

${ }^{\mathrm{A}}$ For the treatments' descriptions, see Table 1. Means followed by different lowercase letters within a column are significantly different $(p<0.05)$. A higher value indicates higher overall acceptability.

\section{Conclusions}

In the present study, GF cookies were prepared from CF, DSF, and MS as gluten replacers. The physicochemical analysis results revealed that incorporating the ingredients, as mentioned earlier, increased the treatments' specific volume and moisture content compared to the control. Regarding color analysis, a decrease of lightness and increase of redness and yellowness were observed in cookies due to the natural pigmentation of the ingredients and the occurrence of Maillard reaction during baking. Moreover, supplementation of these ingredients improved the texture and sensory characteristics of the cookies. Overall, it can be concluded that a GF cookie with acceptable qualitative properties can be prepared using 20\% DSF, 30\% CF, and $0.9 \%$ MS.

\section{Data Availability}

No data were used to support this study.

\section{Conflicts of Interest}

The authors declare that there are no conflicts of interest.

\section{Authors' Contributions}

Mehrdad Mohammadi participated in conceptualization, supervision, data curation, formal analysis, investigation, methodology, original draft preparation, and manuscript review and editing. Nasim Khorshidian contributed to conceptualization, data curation, resources, software, original draft preparation, and manuscript review and editing. Mojtaba Yousefi worked on investigation, software, validation, and visualization. Amin Mousavi Khaneghah was involved in supervision, validation, original draft preparation, and manuscript review and editing. All authors contributed equally to this work.

\section{Acknowledgments}

The authors hereby appreciate the National Nutrition and Food Technology Research Institute (Iran, Tehran) for providing the equipment required for the measurements.

\section{References}

[1] M. DI Cairano, F. Galgano, R. Tolve, M. C. Caruso, and N. Condelli, "Focus on gluten free biscuits: ingredients and issues," Trends in Food Science \& Technology, vol. 81, pp. 203-212, 2018.

[2] Commission, C. A.. 2008. Codex Standard for Foods for Special Dietary Use for Persons Intolerant to Gluten. http:// www. codexalimentarius. net/download/standards/291/cxs_ 118 e. pdf..

[3] S. Insha Rafiq, K. Muzaffar, S. Mansha Rafiq, D. Saxena, and B. Dar, "Underutilized horse chestnut (Aesculus indica) flour and its utilization for the development of gluten-free pasta," Italian Journal of Food Science, vol. 33, no. SP1, pp. 137-149, 2021.

[4] L. T. G. F. Brites, F. Ortolan, D. W. D. Silva et al., "Gluten-free cookies elaborated with buckwheat flour, millet flour and chia seeds," Food Science and Technology, vol. 39, pp. 458-466, 2019.

[5] Y. Gao, M. E. Janes, B. Chaiya, M. A. Brennan, C. S. Brennan, and W. Prinyawiwatkul, "Gluten-free bakery and pasta products: prevalence and quality improvement," International Journal of Food Science and Technology, vol. 53, pp. 19-32, 2018.

[6] S. A. Mir, M. A. Shah, H. R. Naik, and I. A. Zargar, "Influence of hydrocolloids on dough handling and technological properties of gluten-free breads," Trends in Food Science \& Technology, vol. 51, pp. 49-57, 2016.

[7] M. A. Przybysz and E. Dłużewska, "The effect of the addition of water, soy protein, inulin, and maltodextrin on the quality of dough and gluten-free breads," Italian Journal of Food Science, vol. 30, no. 4, 2018.

[8] A. M. Hamdani, I. A. Wani, and N. A. Bhat, "Gluten free cookies from rice-chickpea composite flour using exudate gums from acacia, apricot and karaya," Food Bioscience, vol. 35, Article ID 100541, 2020.

[9] G. Rocchetti, A. Senizza, A. Gallo, L. Lucini, G. Giuberti, and V. Patrone, "In vitro large intestine fermentation of glutenfree rice cookies containing alfalfa seed (Medicago sativa L.) flour: a combined metagenomic/metabolomic approach," Food Research International, vol. 120, pp. 312-321, 2019.

[10] K. N. Jan, P. S. Panesar, and S. Singh, "Optimization of antioxidant activity, textural and sensory characteristics of gluten-free cookies made from whole Indian quinoa flour," Lebensmittel-Wissenschaft \& Technologie, vol. 93, pp. 573582, 2018.

[11] C. W. Simons and C. Hall III, "Consumer acceptability of gluten-free cookies containing raw cooked and germinated 
pinto bean flours," Food Sciences and Nutrition, vol. 6, pp. 77-84, 2018.

[12] H. Doğan and R. Meral, "The effects OF locust bean gum and rhubarb ON the physical and functional properties OF the gluten-free biscuits," Italian Journal of Food Science, vol. 31, 2019.

[13] S. Benkadri, A. Salvador, M. N. Zidoune, and T. Sanz, "Gluten-free biscuits based on composite rice-chickpea flour and xanthan gum," Food Sci. Technol. Int.vol. 24, pp. 607-616, 2018.

[14] G. Giuberti, G. Rocchetti, S. Sigolo, P. Fortunati, L. Lucini, and A. Gallo, "Exploitation of alfalfa seed (Medicago sativa L.) flour into gluten-free rice cookies: nutritional, antioxidant and quality characteristics," Food Chemistry, vol. 239, pp. 679-687, 2018.

[15] C. M. Mancebo, P. Rodriguez, and M. Gómez, "Assessing rice flour-starch-protein mixtures to produce gluten free sugarsnap cookies," Lebensmittel-Wissenschaft und -TechnologieFood Science and Technology, vol. 67, pp. 127-132, 2016.

[16] M. Sakač, M. Pestorić, A. Mišan et al., "Antioxidant capacity, mineral content and sensory properties of gluten-free rice and buckwheat cookies," Food Technology and Biotechnology, vol. 53, pp. 38-47, 2015.

[17] M. Cannas, S. Pulina, P. Conte et al., "Effect of substitution of rice flour with Quinoa flour on the chemical-physical, nutritional, volatile and sensory parameters of gluten-free ladyfinger biscuits," Foods, vol. 9, p. 808, 2020.

[18] M. Paciulli, M. Rinaldi, A. Cavazza et al., "Effect of chestnut flour supplementation on physico-chemical properties and oxidative stability of gluten-free biscuits during storage," Lebensmittel-Wissenschaft und -Technologie, vol. 98, pp. 451457, 2018.

[19] H. Wang, D. Hu, Q. Ma, and L. Wang, "Physical and antioxidant properties of flexible soy protein isolate films by incorporating chestnut (Castanea mollissima) bur extracts," Lebensmittel-Wissenschaft und-Technologie-Food Science and Technology, vol. 71, pp. 33-39, 2016.

[20] N. Aguilar, E. Albanell, B. Miñarro, and M. Capellas, "Chestnut flour sourdough for gluten-free bread making," European Food Research and Technology, vol. 242, no. 10, pp. 1795-1802, 2016.

[21] M. Paciulli, M. Rinaldi, M. Cirlini, F. Scazzina, and E. Chiavaro, "Chestnut flour addition in commercial glutenfree bread: a shelf-life study," Lebensmittel-Wissenschaft und -Technologie, vol. 70, pp. 88-95, 2016.

[22] A. Mishra, M. Devi, and P. Jha, "Development of gluten free biscuits utilizing fruits and starchy vegetable powders," Journal of Food Science \& Technology, vol. 52, no. 7, pp. 4423-4431, 2015.

[23] I. Demirkesen, B. Mert, G. Sumnu, and S. Sahin, "Utilization of chestnut flour in gluten-free bread formulations," Journal of Food Engineering, vol. 101, pp. 329-336, 2010.

[24] I. Demirkesen, O. H. Campanella, G. Sumnu, S. Sahin, and B. R. Hamaker, "A study on staling characteristics of glutenfree breads prepared with chestnut and rice flours," Food and Bioprocess Technology, vol. 7, pp. 806-820, 2014.

[25] I. Demirkesen, E. Puchulu-Campanella, S. Kelkar, O. H. Campanella, G. Sumnu, and S. Sahin, "Production and characterisation of gluten-free chestnut sourdough breads," Quality Assurance and Safety of Crops \& Foods, vol. 8, no. 3, pp. 349-358, 2016.
[26] I. Demirkesen, "Formulation of chestnut cookies and their rheological and quality characteristics," Journal of Food Quality, vol. 39, pp. 264-273, 2016.

[27] P. Littardi, M. Paciulli, E. Carini, M. Rinaldi, M. Rodolfi, and E. Chiavaro, "Quality evaluation of chestnut flour addition on fresh pasta," LWT, vol. 126, Article ID 109303, 2020.

[28] M. Rinaldi, M. Paciulli, A. Caligiani, F. Scazzina, and E. Chiavaro, "Sourdough fermentation and chestnut flour in gluten-free bread: a shelf-life evaluation," Food Chemistry, vol. 224, pp. 144-152, 2017.

[29] M. Miyazaki, P. Van Hung, T. Maeda, and N. Morita, "Recent advances in application of modified starches for breadmaking," Trends in Food Science \& Technology, vol. 17, pp. 591-599, 2006.

[30] J. Oliveira Filho, A. Lemes, R. Cruz Filho et al., "Red pasta: what is the technological impact of the enrichment of beet ingredient in fresh pasta?" Qas, vol. 13, no. 2, pp. 46-55, 2021.

[31] U. Farooq, C. DI Mattia, M. Faieta, F. Flamminii, and P. Pittia, "Colloidal properties and stability of olive oil-in water emulsions stabilized by starch particles," Italian Journal of Food Science, vol. 33, no. 4, pp. 1-10, 2021.

[32] M. Witczak, L. Juszczak, R. Ziobro, and J. Korus, "Influence of modified starches on properties of gluten-free dough and bread. Part I: rheological and thermal properties of gluten-free dough," Food Hydrocolloids, vol. 28, pp. 353-360, 2012.

[33] W. Pongjaruvat, P. Methacanon, N. Seetapan, A. Fuongfuchat, and C. Gamonpilas, "Influence of pregelatinised tapioca starch and transglutaminase on dough rheology and quality of gluten-free jasmine rice breads," Food Hydrocolloids, vol. 36, pp. 143-150, 2014.

[34] Z. Karolini-Skaradzinska, A. Czubaszek, M. Stanislawska, and P. Szewcow, "Changes in baking properties of wheat flour impacted by maltodextrins added," Zywnosc-Nauka Technologia Jakosc, vol. 19, pp. 108-121, 2012.

[35] Y. Kurahashi and Z. Yoshino, "Heat-moisture-treated starch; its production, properties, and uses," Journal of Applied Glycoscience, vol. 47, no. 1, pp. 125-132, 2000.

[36] C. Platat, H. M. Habib, I. B. Hashim et al., "Production of functional pita bread using date seed powder," Journal of Food Science \& Technology, vol. 52, pp. 6375-6384, 2015.

[37] J. Singh, L. Kaur, and O. J. Mccarthy, "Factors influencing the physico-chemical, morphological, thermal and rheological properties of some chemically modified starches for food applications-A review," Food Hydrocolloids, vol. 21, pp. 1-22, 2007.

[38] Aacc International, "Approved methods of analysis," Method 10-05.01 Guidelines for Measurement of Volume by Rapeseed Displacement, Aacc International, Saint Paul, MN, U.S.A, 2000.

[39] M. Mohammadi, N. Sadeghnia, M.-H. Azizi, T.-R. Neyestani, and A. M. Mortazavian, "Development of gluten-free flat bread using hydrocolloids: xanthan and CMC," Journal of Industrial and Engineering Chemistry, vol. 20, pp. 1812-1818, 2014.

[40] F. Ronda, M. Gómez, C. A. Blanco, and P. A. Caballero, "Effects of polyols and nondigestible oligosaccharides on the quality of sugar-free sponge cakes," Food Chemistry, vol. 90, pp. 549-555, 2005.

[41] E. Yildiz and D. Gocmen, "Use of almond flour and stevia in rice-based gluten-free cookie production," Journal of Food Science \& Technology, vol. 58, pp. 940-951, 2021. 
[42] M. Mohammadi, M.-H. Azizi, T. R. Neyestani, H. Hosseini, and A. M. Mortazavian, "Development of gluten-free bread using guar gum and transglutaminase," Journal of Industrial and Engineering Chemistry, vol. 21, pp. 1398-1402, 2015.

[43] M. M. Martínez and M. Gómez, "Rheological and microstructural evolution of the most common gluten-free flours and starches during bread fermentation and baking," Journal of Food Engineering, vol. 197, pp. 78-86, 2017.

[44] S. K. Ghodke, L. Ananthanarayan, and L. Rodrigues, "Use of response surface methodology to investigate the effects of milling conditions on damaged starch, dough stickiness and chapatti quality," Food Chemistry, vol. 112, pp. 1010-1015, 2009.

[45] A. Sae-Eaw, P. Chompreeda, W. Prinyawiwatkul et al., "Acceptance and purchase intent of US consumers for nonwheat rice butter cakes," Journal of Food Science, vol. 72, pp. S92-S97, 2007.

[46] O. Yildiz and I. S. Dogan, "Optimization of gluten-free cake prepared from chestnut flour and transglutaminase: response surface methodology approach," International Journal of Food Engineering, vol. 10, pp. 737-746, 2014.

[47] M. V. Ostermann-Porcel, N. Quiroga-Panelo, A. N. Rinaldoni, and M. E. Campderrós, "Incorporation of okara into gluten-free cookies with high quality and nutritional value," Journal of Food Quality, vol. 2017, Article ID 4071585, 2017.

[48] K. Shevkani, N. Singh, A. Kaur, and J. C. Rana, "Physicochemical, pasting, and functional properties of amaranth seed flours: effects of lipids removal," Journal of Food Science, vol. 79, pp. C1271-C1277, 2014.

[49] L. Dokić, I. Nikolić, D. Šoronja-Simović, B. Pajin, and N. Juul, "Sensory characterization of cookies with chestnut flour," International Journal of Nutrition and Food Engineering, vol. 8, pp. 416-419, 2014.

[50] N. Bozdogan, S. Kumcuoglu, and S. Tavman, "Investigation of the effects of using quinoa flour on gluten-free cake batters and cake properties," Journal of Food Science \& Technology, vol. 56, pp. 683-694, 2019.

[51] C. Fadda, A. M. Sanguinetti, A. Del Caro, C. Collar, and A. Piga, "Bread staling: updating the view," Comprehensive Reviews in Food Science and Food Safety, vol. 13, pp. 473-492, 2014.

[52] S. Z. Asadi, M. A. Khan, and R. V. Chamarthy, "Development and quality evaluation of cookies supplemented with concentrated fiber powder from chiku (Manilkara zapota L.)," Journal of Food Science \& Technology, vol. 58, no. 5, pp. 1-9, 2020.

[53] S. A. Mir, S. J. D. Bosco, and M. A. Shah, "Technological and nutritional properties of gluten-free snacks based on brown rice and chestnut flour," Journal of the Saudi Society of Agricultural Sciences, vol. 18, pp. 89-94, 2019.

[54] V. Giannou, D. Lebesi, and C. Tzia, "Packaging and shelf-life prediction of bakery products." in W. Zhou, Y. H. Hui, I. De Leyn, M. A. Pagani, C. M. Rosell, J. D. Selman, \& N. Therdthai (Eds.), Bakery Products Science and Technology, pp. 355-371, 2nd ed., John Wiley \& Sons, Ltd., Chichester, UK, 2014.

[55] L. A. Belcourt and T. P. Labuza, "Effect of raffinose on sucrose recrystallization and textural changes in soft cookies," Journal of Food Science, vol. 72, pp. C065-C071, 2007.

[56] K. N. De Simas, L. D. N. Vieira, R. Podestá et al., "Effect of king palm (Archontophoenix alexandrae) flour incorporation on physicochemical and textural characteristics of gluten-free cookies," International Journal of Food Science and Technology, vol. 18, 2009.
[57] C. M. Rosell, J. A. Rojas, and C. Benedito de Barber, "Influence of hydrocolloids on dough rheology and bread quality," Food Hydrocolloids, vol. 15, pp. 75-81, 2001.

[58] S. A. O. Adeyeye, "Quality evaluation and acceptability of cookies produced from rice (oryza glaberrima) and soybeans (Glycine max) flour blends," Journal of Culinary Science \& Technology, vol. 18, pp. 54-66, 2020. 